\title{
Clinical challenges in the management of osteoporosis
}

\author{
Sheryl F Vondracek' \\ Paul Minne ${ }^{2}$ \\ Michael T McDermott ${ }^{3}$ \\ 'Department of Clinical Pharmacy, \\ University of Colorado at Denver and \\ Health Sciences Center, Denver, CO, \\ USA; ${ }^{2}$ Amgen Medical Affairs, Denver, \\ CO, USA; ${ }^{3}$ Director of the Endocrine \\ and Diabetes Practice, Department of \\ Medicine, University of Colorado at \\ Denver and Health Sciences Center, \\ Denver, CO, USA
}

\begin{abstract}
While knowledge regarding the diagnosis and treatment of osteoporosis has expanded dramatically over the last few years, gaps in knowledge still exist with guidance lacking on the appropriate management of several common clinical scenarios. This article uses fictional clinical scenarios to help answer three challenging questions commonly encountered in clinical practice. The first clinical challenge is when to initiate drug therapy in a patient with low bone density. It is estimated that 34 million America have low bone density and are at a higher risk for low trauma fractures. Limitations of using bone mineral density alone for drug therapy decisions, absolute risk assessment and evidence for the cost-effectiveness of therapy in this population are presented. The second clinical challenge is the prevention and treatment of vitamin D deficiency. Appropriate definitions for vitamin D insufficiency and deficiency, the populations at risk for low vitamin, potential consequences of low vitamin $\mathrm{D}$, and how to manage a patient with low vitamin $\mathrm{D}$ are reviewed. The third clinical challenge is how to manage a patient receiving drug therapy for osteoporosis who has been deemed a potential treatment failure. How to define treatment failure, common causes of treatment failure, and the approach to the management of a patient who is not responding to appropriate osteoporosis therapy are discussed.
\end{abstract}

Keywords: osteoporosis, osteopenia, bisphosphonate, vitamin D, dual-energy X-ray absorptiometry

\section{Introduction}

With the aging of society, the prevention and treatment of osteoporosis has become a more recognized concern. The widespread availability of bone density screening and the development of efficacious therapies that increase bone density and reduce fracture risk have resulted in more patients being evaluated and managed for osteoporosis. Still, many challenging patient scenarios exist in clinical practice where guidance is lacking on appropriate management. This paper summarized three clinical scenarios that are frequently faced by primary care providers in practice and gives guidance on how to approach the management of these osteoporosis-related challenges. The first challenge discusses the management of low bone density and when to consider the initiation of pharmacologic therapy. The second challenge is preventing and treating vitamin $\mathrm{D}$ deficiency in the elderly. The third challenge is how to manage a patient that is deemed a potential treatment failure.

\section{Clinical challenge \# I: Low bone density - When to initiate drug therapy? Clinical scenario}

A 58-year-old Caucasian woman presents for follow-up of her central dual-energy $\mathrm{X}$-ray absorptiometry (DXA) results that indicate low bone density (T-score lumbar spine $=-1.8, \mathrm{~T}$-score total hip $=-1.6$, and $\mathrm{T}$-score femoral neck $=-1.4$ ). Her past medical history is significant only for hypertension and mild gastroesophageal 
reflux disease for which she takes hydrochlorothiazide and esomeprazole orally once daily. Her family history is significant for a mother who had a hip fracture at the age of 85 years. She has smoked 1 pack of cigarettes per day for last 38 years and occasionally drinks alcohol. She does not routinely exercise. Her current weight is $65 \mathrm{~kg}$ and height is 5 feet, 5 inches or $162.5 \mathrm{~cm}$ tall.

Approximately 10 million Americans have osteoporosis and an additional 34 million have low bone mass or osteopenia as defined by the World Health Organization (WHO) (Table 1) (Kanis and Gluer 2000; US Department of Health and Human Services 2004). This categorization is based solely on bone mineral density (BMD) T-scores, which is the number of standard deviations the patient's BMD is below or above the mean BMD of a young, healthy, sex-matched reference population, using central DXA. BMD measurements are the most clinically used and accepted predictors of fracture risk. While BMD accounts for up to $70 \%$ of bone strength, there are limitations to using BMD alone for this purpose (Kanis et al 2001b; Schuit et al 2004; Siris et al 2004; SornayRendu et al 2005; Wainwright et al 2005). First, absolute BMD using DXA does not provide information regarding the quality of the bone. Bone strength depends on its mass, size, shape, degree of mineralization, microarchitecture, and the intrinsic properties of the materials that comprise the bone (Bouxsein 2005; Felsenberg and Boonen 2005). The two dimensional or areal depiction provided by DXA quantifies only the mass, size, and degree of mineralization, limiting its ability to reflect total bone strength and the bone's risk for fracture (Kanis 2002). Alternative noninvasive technologies, such as 3-dimentional magnetic resonance microimaging and microcomputed tomography, are currently under investigation to improve bone strength measurement and fracture prediction (Felsenberg and Boonen 2005). Second, there are potential errors that exist when measuring BMD with central DXA. Improper placement of the patient on the instrument, patient movement during the scan, inaccurate calibration of the machine, the presence of vascular calcification or arthritic

Table I World health organization bone mineral density (BMD) criteria (Kanis and Gluer 2000) ${ }^{\mathbf{a}}$

\section{Normal}

Low bone mass (osteopenia)

Osteoporosis
BMD T-score at -1.0 and above. BMD T-score between -1 and -2.5 . BMD T-score at or below -2.5 . Women in this group with one or more fractures are considered to have severe osteoporosis.

Notes: 'Based on BMD using DXA at the spine, hip, or wrist in white postmenopausal women. artifacts, and inappropriate interpretation of the DXA results by the practitioner can all negatively impact the value of the BMD results for fracture prediction.

While the WHO diagnostic criteria are helpful for establishing prevalence and incidence of disease, they cannot be relied upon alone to guide treatment decisions. BMD is only one of many factors that independently influences fracture risk. Age and previous history of fracture are strong independent predictors of fracture risk (Sornay-Rendu et al 2005). According to a study by Kanis and colleagues (2002), older postmenopausal women have up to a 7-fold higher risk for fracturing than younger postmenopausal women at the exact same BMD. BMD was measured in 616 postmenopausal women who were then followed for a median of 5.6 years to determine the incidence of fractures. At baseline, $48 \%$ of women had osteopenia and $14.5 \%$ had osteoporosis. On follow-up, $73.1 \%$ of all fractures occurred in women without osteoporosis. Women with BMD in the osteopenia range and prevalent fracture were at higher risk for subsequent fracture than women with BMD in the osteoporotic range, but without prevalent fracture (Pasco et al 2006). Other known risk factors for osteoporosis are listed in Table 2.

There clearly exists a gap in defining and identifying those at both low and high risk for osteoporotic fractures. The decision to treat a patient to prevent fractures should ideally be based on a patient's own absolute risk profile. Absolute fracture risk can be more accurately predicted by utilizing risk factors such as age, prior fracture, and family history in combination with BMD values than on BMD criteria alone (Kanis et al 2001a, 2007). An absolute fracture risk assessment tool that can be used with or without BMD measurement results is currently being designed by the WHO and holds promise to be a more sensitive assessment of facture risk (Kanis et al 2005). This much anticipated absolute risk assessment will use several easily identifiable clinical risk factors which act independently of bone mineral density to increase the risk of fracture. Factors such as age, previous fracture, family history of hip fracture, glucocorticoid use, current smoking, and alcohol use $>2$ drinks/day are being considered for the assessment tool. Similar to many other disease states that use a widely accepted and mainstream assessment tool to predict future clinical outcomes, this fracture assessment will provide an individual's percent absolute probability of fracturing within the next 10 years. Clinician and third party payer acceptance of this tool are expected to be large barriers to its success, but there are several advantages that should be 
Table 2 Risk factors (besides low bone mass) for osteoporotic fracture in postmenopausal women

\begin{tabular}{|c|c|}
\hline \multicolumn{2}{|c|}{ Major risk factors (independent of bone mass) } \\
\hline$\bullet$ & Advanced age $\mathrm{e}^{\mathrm{a}, \mathrm{b}}$ \\
\hline$\bullet$ & Personal history of fracture as an adult (after age 45 years) \\
\hline$\bullet$ & History of low trauma facture in a first-degree relative ${ }^{\mathrm{a}, \mathrm{b}}$ \\
\hline$\bullet$ & Low body weight (less than 127 lbs or $58 \mathrm{~kg})^{\mathrm{a}, \mathrm{b}}$ \\
\hline$\bullet$ & Current smoker \\
\hline • & Use of systemic glucocorticoids (for 3 or more months) ) $^{a, b}$ \\
\hline$\bullet$ & Rheumatoid arthritis ${ }^{b}$ \\
\hline$\bullet$ & Alcohol intake $>2$ servings per day \\
\hline \multicolumn{2}{|c|}{ Additional risk factors } \\
\hline$\bullet$ & Recent falls or having a tendency to fall \\
\hline • & Female \\
\hline - & Caucasian or Asian race \\
\hline • & Estrogen deficiency before age 45 years \\
\hline • & Dementia \\
\hline • & Lifelong low calcium intake \\
\hline • & Vitamin $\mathrm{D}$ deficiency \\
\hline - & Low physical activity \\
\hline
\end{tabular}

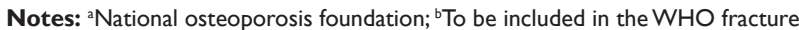
risk assessment tool (National Osteoporosis Foundation 2003; Kanis et al 2005)

considered. Having a simple and clearer treatment decision line is undoubtedly needed. Since central DXA is not always easily accessible in all parts of the world, this opens up alternative methods for determining fracture risk and treatment thresholds. For payers and medical societies providing new guidelines, this tool will simply define absolute risk and any intervention thresholds can still be defined nationally based on accepted medical practices as well as the ability to pay.

For a Caucasian woman between the ages of 50-59 years, the prevalence of osteoporosis is approaching $15 \%$ and rises with increasing age. Another $30 \%-50 \%$ in this population has low bone density (osteopenia), which places them at increased risk for osteoporosis and fracture. Approximately half of the patients with fracture do not have osteoporosis based on WHO criteria (Melton et al 1993; Pasco et al 2006). The National Osteoporosis Risk Assessment (NORA) study evaluated the association between peripheral BMD and fracture risk over 1 year in over 200,000 postmenopausal women without a diagnosis of osteoporosis (Siris et al 2001; Miller et al 2002). Overall, 39.6\% of the population evaluated had BMD T-scores within the osteopenic range. While fracture risk was highest among women with osteoporosis, the majority of fractures overall (52\%) occurred in the group of women with osteopenia (Siris et al 2004). These data support the fact that low bone density cannot be used as the sole determinant of fracture risk as many women with bone densities in the osteopenic range are at risk for low trauma fractures.
All guidelines consistently recommend initiating pharmacologic therapy in postmenopausal women with osteoporosis (T-score at or below -2.5) or with a low trauma fracture of the spine or hip. In addition, the National Osteoporosis Foundation (NOF) recommends that drug therapy be considered in postmenopausal women with BMD T-scores below -2.0 in the absence of risk factors and at a $\mathrm{T}$-score below -1.5 with one or more major risk factors for fracture (National Osteoporosis Foundation 2003). In contrast, the North American Menopause Society recommends adding pharmacologic therapy if the T-score is between -2.0 and -2.5 only in women with at least one additional major risk factor (North American Menopause Society 2006). Data from NORA suggest a peripheral BMD T-score of -1.8 or less accurately identifies postmenopausal women at high risk for fracture risk at 1 year and can be useful to guide treatment decisions (Miller et al 2004).

Since low bone density is a silent risk factor for subsequent fracture, women of all ages should be counseled on preventing osteoporosis. A bone-healthy lifestyle is key (Lock et al 2006). The presence of modifiable risk factors (such as current smoking) should be carefully reviewed and addressed. Regular weight-bearing and muscle-strengthening exercises, as well as balance training exercises should be recommended to reduce the risk of falls. Women should be advised to limit alcohol intake to ideally less than one serving per day. Adequate vitamin $\mathrm{D}$ and calcium intake is paramount. A minimum intake of 1000-1200 mg of dietary and supplemental calcium and 400-1000 units of vitamin D is recommended for osteoporosis prevention/treatment (Standing Committee on the Scientific Evaluation of Dietary Reference Intakes 1997; Dawson-Hughes et al 2005; National Osteoporosis Foundation 2007).

The primary goal of pharmacologic therapy should be fracture prevention. Several medications are FDA-indicated for the prevention of osteoporosis. Studies have demonstrated improvements in BMD and bone turnover markers with these therapies; however, data regarding the effect on fracture risk is limited (Hosking et al 1998; Mortensen et al 1998). While improvements in BMD and bone turnover are important, changes in these parameters do not always directly correlate with fracture risk reduction (Sarkar et al 2002; Small 2005).

The oral bisphosphonates alendronate, risedronate, and ibandronate are FDA-indicated for both prevention and treatment of postmenopausal osteoporosis. Evidence from studies of postmenopausal women with osteoporosis has shown that all approved oral bisphosphonates significantly increase BMD and reduce vertebral fracture risk (Black et al 
1996; Harris et al 1999; Chesnut et al 2004). Alendronate and risedronate have also been shown to reduce the risk for hip fractures (Black et al 1996; McClung et al 2001). Studies of oral bisphosphonate therapy in postmenopausal women with bone densities in the osteopenic or normal range have typically not evaluated the effect on fracture risk (Hosking et al 1998; Mortensen et al 1998). The fracture intervention trial with alendronate did enroll some postmenopausal women with osteopenia. In a subgroup analysis of this study, women with T-scores between -1.6 and -2.5 without fractures at baseline were shown to have a significant reduction in vertebral fracture risk (Quandt et al 2005). Oral bisphosphonates are safe and generally well tolerated. Upper gastrointestinal symptoms such as dyspepsia are the most common side effects seen with oral bisphosphonate therapy. Patients need to adhere to the strict administration guidelines to minimize these effects.

Intravenous (IV) bisphosphonates (ibandronate and zoledronic acid) have not been studied in women with osteopenia and therefore are not FDA-indicated for the prevention of osteoporosis. However, they may be an option for osteoporosis prevention in postmenopausal women with documented poor adherence, who cannot tolerate oral bisphosphonate therapy due to gastrointestinal side effects or cannot take oral therapy due to issues related to malabsoption. Infusionrelated, flu-like symptoms tend to the most common side effects associated with IV bisphosphonate therapy (Delmas et al 2006; Black et al 2007).

Hormone therapy (HT) is approved only for the prevention of postmenopausal osteoporosis. While HT reduces the risk of spine and hip fractures by $34 \%$, its use resulted in increased risk for breast cancer, heart attack, stroke, and venous thromboembolism (VTE) (Rossouw et al 2002). Since the risks potentially outweigh the benefits, HT is no longer considered a first line therapy option for osteoporosis prevention. In alliance with current FDA and North American Menopause Society recommendations, estrogens should be reserved to treat moderate to severe menopausal symptoms and should only be used for as short of time as possible (The North American Menopause Society 2006, 2007). HT should only be considered for osteoporosis prevention in postmenopausal women for whom other medications are considered to be unsuitable and after careful review of the risks and benefits.

Raloxifene is an estrogen agonist-antagonist (EAA) that is approved for the prevention and treatment of postmenopausal osteoporosis. Raloxifene has been shown to increase femoral neck and spine BMD in postmenopausal women with normal to low bone density at baseline and to reduce the risk for spine factures by $50 \%$ in postmenopausal women with bone density in the osteoporotic range without baseline vertebral fracture (Ettinger et al 1999; Kanis et al 2003). Possible side effects include increases in hot flashes, and increased VTE and fatal stroke risk (Ettinger et al 1999; Wooltorton 2006). One potential benefit of raloxifene is the prevention of breast cancer. The Raloxifene Use for The Heart (RUTH) trial showed that raloxifene reduced the relative risk of estrogen-receptor positive invasive breast cancer by $55 \%$ over a five year period (Barrett-Connor et al 2006). Raloxifene is also FDA-indicated to reduce the risk for invasive breast cancer in postmenopausal women with osteoporosis (Vogel et al 2006).

Teriparatide (recombinant parathyroid hormone), a daily administered subcutaneous anabolic agent, is not FDAindicated for the prevention of osteoporosis in postmenopausal women. However, in postmenopausal women with osteoporosis and prevalent fractures, teriparatide reduced the risk of vertebral fractures and nonvertebral fractures over a 19 month period (Neer et al 2001). Teriparatide is generally well tolerated and the most common side effects include transient hypercalcemia, leg cramps, and dizziness. The long-term safety of teriparatide is unknown and the use is limited to 2 years. Since teriparatide is not approved as a preventative agent, it should only be considered if no other agents are appropriate or tolerated by the patient.

Strontium ranelate is approved by the European Union for the prevention and treatment of postmenopausal osteoporosis. Strontium, a once daily oral product, has a novel mechanism of action acting on both bone resorption and bone formation. Studies have demonstrated a significant increase in BMD in postmenopausal women with normal to low bone density (Reginster et al 2002; O'Donnell et al 2006). A pooled analysis of studies in postmenopausal women with at least one baseline vertebral fracture or nonvertebral fracture demonstrated a $37 \%$ reduction in vertebral fractures and a $14 \%$ reduction in nonvertebral fractures (Meunier et al 2002, 2004; Reginster et al 2002, 2005; O’Donnell et al 2006). The main side effects include diarrhea and headache. In addition, an increased risk for VTE has been reported (O'Donnell et al 2006). Strontium is an alternative to oral bisphosphonates for the prevention of osteoporosis.

Pharmacologic therapy is indicated and considered costeffective for most postmenopausal women with BMD Tscores at or below -2.5 or with a low trauma fracture of the hip, spine or wrist. The initiation of drug therapy for women who do not meet these criteria is controversial. Five years of alendronate therapy was found not to be cost-effective 
in postmenopausal white women with T-scores better than -2.5 and no additional risk factors (Schousboe et al 2005b).

The societal cost per quality-adjusted life-year (QALY) gained was estimated at US\$70,000-332,000 depending on age and BMD. The presence of additional independent risk factors for fracture would be needed to bring this value to below the commonly accepted cost per QALY of US $\$ 50,000$. This study clearly demonstrated that treatment based only on low bone density was not cost effective. In a similar analysis, the same authors determined that alendronate therapy would be cost-effective in women with one or more prevalent vertebral deformities and osteopenia (Schousboe et al 2005a).

\section{Management of this patient}

Based on the WHO criteria, this patient has low bone mass or osteopenia. In addition to her low BMD, she has additional independent risks for fracture including a family history of osteoporosis in a primary degree relative and being a current smoker. According to the NOF guidelines, this patient should be considered for pharmacologic therapy based on a T-score below -1.5 at the total hip and spine and the presence of at least one major risk factor. Based on her age of 58 years, she is at a significantly lower 10-year risk for fracture compared to an older woman with similar risk factors and BMD. However, she is probably at a high enough risk to warrant consideration of pharmacologic therapy. This is a prime example of a patient where the WHO's absolute risk assessment tool will be valuable.

At minimum this patient should be educated on a healthy bone lifestyle with an emphasis on smoking cessation, exercise and adequate calcium and vitamin D intake. The decision to initiate pharmacological therapy should be made in conjunction with the patient. Adherence rates with these therapies tend to be low and poor adherence has been linked to poor outcomes (Siris et al 2006; Weycker et al 2007). It is important that the patient fully understands any risks and expected benefits of therapy. If pharmacologic treatment is selected, an oral bisphosphonate would be the drug of choice. Drug treatment may not be life-long in this patient. Women without evidence of a low trauma fracture and who have responded well to bisphosphonate therapy with BMD T-scores maintained in the osteopenic range are being considered for a "drug holiday" with close monitoring. Studies have demonstrated prolonged suppression of bone turnover and maintenance of BMD in some women after discontinuation of alendronate therapy (Black et al 2006). If pharmacologic treatment is deferred, the patient can be safety monitored for significant decreases in BMD with serial DXA scans or biomarkers of bone turnover.

\section{Clinical challenge \#2: Prevention/ management of vitamin $D$ deficiency \\ Clinical scenario}

An 84-year-old African American woman presents for follow-up of laboratory studies that were drawn at her last clinic visit after her central DXA bone density results revealed osteoporosis $(\mathrm{T}$-score lumbar spine $=-2.8, \mathrm{~T}$-score total hip $=-2.2$, and $\mathrm{T}$-score femoral neck $=-2.4)$. Pertinent laboratory values were as follows: 25-hydroxyvitamin D (25-OHD) concentration $=22 \mathrm{nmol} / \mathrm{L}(9 \mathrm{ng} / \mathrm{mL})$, complete blood count $(\mathrm{CBC})=$ within normal limits, blood urea nitrogen $(\mathrm{BUN})=$ $2.9 \mathrm{mmol} / \mathrm{L}(8 \mathrm{mg} / \mathrm{dL})$, serum creatinine $(\mathrm{Scr})=80 \mu \mathrm{mol} / \mathrm{L}$ $(0.9 \mathrm{mg} / \mathrm{dL})$, liver function tests $(\mathrm{LFTs})=$ within normal limits, albumin $=35 \mathrm{~g} / \mathrm{L}(3.5 \mathrm{~g} / \mathrm{dL})$, calcium $=2.3 \mathrm{mmol} / \mathrm{L}$ $(9.2 \mathrm{mg} / \mathrm{dL})$, phosphorous $=0.9 \mathrm{mmol} / \mathrm{L}(2.8 \mathrm{mg} / \mathrm{dL})$, parathyroid hormone $=75 \mathrm{ng} / \mathrm{L}(75 \mathrm{pg} / \mathrm{mL})$.

Adequate serum vitamin D concentrations are important for the maintenance of skeletal health and play a potential beneficial role in extraskeletal organ systems as well. Vitamin D is important for calcium homeostasis. Inadequate levels of vitamin D can lead to insufficient calcium absorption and decreased serum calcium. To compensate, parathyroid hormone (PTH) secretion is increased. In turn, PTH decreases calcium excretion in the kidneys and increases bone resorption to mobilize calcium stores in the bone, increasing serum calcium. Prolonged, severe vitamin D deficiency can lead to poor bone mineralization and osteomalacia. Several studies have demonstrated a decrease in calcium absorption and an increase in PTH in the face of low vitamin D levels (Malabanan et al 1998; Thomas et al 1998; Heaney et al 2003). Low vitamin D levels have been associated with increases in bone turnover, low BMD, and an increased risk for fractures (LeBoff et al 1999). Vitamin D receptors are present within the muscle tissue (Pfeifer et al 2002; Bischoff et al 2003). Cross-sectional studies have demonstrated vitamin D levels correlate with markers of muscle strength and neuromuscular coordination (Dhesi et al 2002; Pfeifer et al 2002; Vieth 2005). In addition, studies have demonstrated an increase in falls in patients with low vitamin D concentrations (Stein et al 1999; Pasco et al 2004). More recently evidence supports inadequate concentrations of vitamin D may be involved in the pathogenesis of several disease states such as cancer, cardiovascular disease, diabetes, multiple sclerosis, and rheumatoid arthritis (Holick 2006; Lappe et al 2007; Martins et al 2007). 
Serum 25-OHD is the best indicator of vitamin D status. There continues to be debate as to the optimal serum concentrations of 25-OHD and there is no consensus on the recommended cut-points for deficiency, insufficiency and sufficiency (Dawson-Hughes et al 2005; Bischoff-Ferrari et al 2006). Several studies have shown that serum concentrations of 25-OHD of at least 50-75 nmol/L (20-30 ng/ml) are necessary to maximize intestinal calcium absorption and minimize secondary hyperparathyroidism (Chapuy et al 1997; Malabanan et al 1998; Heaney et al 2003; Greenspan et al 2005; Levis et al 2005). However, some evidence suggests that optimal fracture and fall prevention occurs with a mean 25-OHD concentration of approximately $100 \mathrm{nmol} / \mathrm{L}$ (40 ng/ml) (Bischoff-Ferrari et al 2006). Most experts do agree that the risk for osteomalacia is increased when 25 OHD concentrations fall below $20-25 \mathrm{nmol} / \mathrm{L}$ ( $8-10 \mathrm{ng} / \mathrm{ml}$ ) (Hanley and Davison 2005). Based on these data reasonable cut-points that define vitamin D deficiency, insufficiency and sufficiency are summarized in Table 3.

Several studies have demonstrated a high prevalence of vitamin D deficiency and insufficiency regardless of the geographical location or latitude, age, or health status of the subjects. (van der Wielen et al 1995; Chapuy et al 1997; Thomas et al 1998; Harris et al 2000; Lips et al 2001; Vieth et al 2001; Greenspan et al 2005). A study of older adults in south Florida revealed a 39\% prevalence of vitamin D insufficiency (defined as a $25-\mathrm{OHD}$ concentration $<50 \mathrm{nmol} / \mathrm{L}$ or $20 \mathrm{ng} / \mathrm{mL}$ ) and a $9 \%$ prevalence of severe deficiency (defined as a $25-\mathrm{OHD}$ concentration $<30 \mathrm{nmol} / \mathrm{L}$ or $12 \mathrm{ng} / \mathrm{mL}$ ) (Levis et al 2005). In a study of general medical patients in Boston, $57 \%$ were considered vitamin D deficient (25-OHD $\leq 38$ $\mathrm{nmol} / \mathrm{L}$ or $15 \mathrm{ng} / \mathrm{mL}$ ) (Thomas et al 1998). In a subgroup of 77 patients who were $<65$ years of age and had no identifiable risk factors for vitamin D deficiency, the incidence of low vitamin D was still high at $42 \%$. Vitamin D status was evaluated in a prospective cohort study of North American postmenopausal women receiving drug therapy for osteoporosis (Holick et al 2005). The majority (91.5\%) were white, and they were fairly evenly distributed geographically. The mean \pm SD serum 25 -OHD was approximately $75 \mathrm{nmol} / \mathrm{L}$

Table 3 Suggested cut-points for serum 25-hydroxyvitamin D concentrations (Dawson-Hughes et al 2005; Holick 2006, 2007)

\begin{tabular}{ll}
\hline Category & 25 -hydroxyvitamin D \\
Deficient & $\leq 25 \mathrm{nmol} / \mathrm{L}(\leq 10 \mathrm{ng} / \mathrm{mL})$ \\
Insufficient & $26-74 \mathrm{nmol} / \mathrm{L}(\mathrm{II}-29 \mathrm{ng} / \mathrm{mL})$ \\
Sufficient & $75-125 \mathrm{nmol} / \mathrm{L}(30-50 \mathrm{ng} / \mathrm{mL})^{\mathrm{a}}$ \\
\hline
\end{tabular}

Notes: ${ }^{\text {DDo }}$ not exceed concentrations $\geq 250 \mathrm{nmol} / \mathrm{L}(\geq 100 \mathrm{ng} / \mathrm{mL}$ ).
$(30 \mathrm{ng} / \mathrm{mL}$ ) in these women, with $52 \%$ of concentrations at $<75 \mathrm{nmol} / \mathrm{L}(30 \mathrm{ng} / \mathrm{mL}), 8 \%<38 \mathrm{nmol} / \mathrm{L}(15 \mathrm{ng} / \mathrm{mL})$, and $1 \%<23 \mathrm{nmol} / \mathrm{L}(9 \mathrm{ng} / \mathrm{mL})$. In a multivariate analysis, eight variables were associated with low serum vitamin D concentrations in this population including age $>80$ years, nonwhite, $\mathrm{BMI}>30 \mathrm{~kg} / \mathrm{m}^{2}$, medications that affect vitamin D metabolism, vitamin D supplementation $<400$ units/day, lack of exercise, lack of discussion with physician on importance of vitamin $\mathrm{D}$ and $<12$ th grade education. There was no association with latitude.

The first step in the systemic activation of vitamin D3 is through the conversion of cutaneous 7-dehydrocholesterol by exposure to ultraviolet B (UV-B) light. Synthesis of vitamin D3 can be reduced by factors that reduce the penetration of the UV-B rays into the skin such as sunscreen, clothing and darkly pigmented skin (Reginster 2005). Ethnic and racial groups with darker skin pigmentation may be at higher risk for vitamin D deficiency (Harris et al 2000; Nesby-O'Dell et al 2002). Wintertime vitamin D status was evaluated in community-dwelling, low income elderly (Harris et al 2000). Twenty one percent of the black subjects had a 25-OHD level of $<25 \mathrm{nmol} / \mathrm{L}$ ( $10 \mathrm{ng} / \mathrm{mL}$ ) compared to only $11 \%$ of white subjects. The mean plasma 25-OHD was about 30\% lower in the black subjects compared to the white subjects. Data from the third National Health and Nutrition Examination Survey (NHANES III) was used to examine the prevalence of vitamin D deficiency among African American women and white women aged 15-49 years (Nesby-O'Dell et al 2002). The mean 25-OHD serum concentration was approximately $45 \mathrm{nmol} / \mathrm{L}(18 \mathrm{ng} / \mathrm{mL})$ for African American women and $83 \mathrm{nmol} / \mathrm{L}(33 \mathrm{ng} / \mathrm{mL})$ for white women. The prevalence of low vitamin D (defined as a 25-OHD concentration $<38 \mathrm{nmol} / \mathrm{L}(15 \mathrm{ng} / \mathrm{mL})$ was $42 \%$ in African American women compared with only $4 \%$ in white women.

Vitamin D assays are expensive with a typical cost of over US\$100 per test and there is concern regarding the variability in 25-OHD measurements, with different laboratories yielding vastly different results depending on the assay used (Binkley et al 2004; Glendenning and Fraser 2005; Holick 2005; Leventis et al 2005). Therefore, routine screening of vitamin D status cannot be recommended at this time. However, a 25-OHD measurement should be considered in anyone at high risk for vitamin D deficiency such as patients with documented low bone density, history of a low trauma fracture or frequent falls, medical conditions causing malabsorption (for example Celiac disease or inflammatory bowel disease), history of unexplained muscle/bone pain, or on medications known to affect vitamin D metabolism 
(for example antiepileptic medications). In addition, a 25-OHD measurement should be considered in all elderly patients and persons with dark pigmented skin that have minimal to no sun-exposure and/or are not taking a daily multivitamin or additional vitamin D supplements.

Several studies have demonstrated a beneficial effect of vitamin D3 (typically in conjunction with adequate calcium intakes) on BMD, fractures, and falls (Chapuy et al 1992, 1994, 2002; Lips et al 1996; Dawson-Hughes et al 1997; Pfeifer et al 2000; Bischoff et al 2003; Trivedi et al 2003; Bischoff-Ferrari et al 2004; Flicker et al 2005; Broe et al 2007). The effects of calcium and vitamin D supplementation on bone density and nonvertebral fractures were evaluated in a double-blind, placebo-controlled trial of 389 healthy, ambulatory men and women over 65 years of age (Dawson-Hughes et al 1997). Subjects were randomly assigned to $500 \mathrm{mg}$ calcium plus 700 units cholecalciferol (vitamin D3) or placebo. After 3 years, significantly higher BMD at the femoral neck, lumbar spine and total body were noted. In addition, there was a statistically significant 50\% relative risk reduction in nonvertebral fractures with 11 fractures occurring in the calcium-vitamin D group and 26 occurring in the placebo group.

The effectiveness of oral cholecalciferol supplementation on the prevention of hip and nonvertebral fractures in adults (age $>60$ years) was evaluated in a meta-analysis of double blind, randomized, controlled trials. Due to heterogeneity, vitamin D trials were pooled according to doses used (high $=$ $700-800$ units/day and low $\leq 400$ units/day). Five trials evaluated hip fracture risk. The 3 high dose trials demonstrated a statistically significant $26 \%$ relative risk reduction in hip fractures. For the two low dose trials, there was no significant difference in hip fracture risk. Seven trials evaluated nonvertebral fracture risk with similar results. Pooled results from the 5 high dose trials revealed a statistically significant $23 \%$ relative risk reduction in nonvertebral fractures. There was no difference in nonvertebral fracture risk for the pooled results of two low dose trials. A significant inverse relationship between hip fracture and nonvertebral fracture risk and achieved 25-OHD levels was noted. The estimated number needed to treat (NNT) was 45 to prevent one hip fracture and 27 to prevent one nonvertebral fracture.

Vitamin D supplementation may improve neuromuscular function in the elderly and possibly reduce their risk for falls (Pfeifer et al 2000; Bischoff et al 2003; Bischoff-Ferrari et al 2004; Dhesi et al 2004). In a double-blind placebo-controlled study, a single 600,000 units intramuscular injection of ergocalciferol (vitamin D2) resulted in a statistically significant, yet modest, improvement in aggregate functional performance time, choice reaction time and postural sway compared with placebo (Dhesi et al 2004). There was no difference in falls over the 6-month study. In a 12-week, double-blind randomized controlled trial of elderly women living in a long-stay geriatric care unit, $1200 \mathrm{mg}$ calcium plus 800 units cholecalciferol was shown to significantly improve musculoskeletal function and reduce falls compared with calcium alone (Bischoff et al 2003). A meta-analysis of 5 double-blind, randomized controlled trials representing 1237 patients demonstrated a statistically significant $22 \%$ reduction in falls with vitamin D treatment compared to calcium alone or placebo (Bischoff-Ferrari et al 2004). The estimated NNT to prevent one fall was 15 patients.

The trials evaluating vitamin D supplementation include mainly white subjects (Bischoff-Ferrari et al 2005). In one prospective, controlled trial of African American postmenopausal women, calcium plus 2000 units/day cholecalciferol did not decrease the rate of bone loss compared with placebo. Fracture risk and falls were not evaluated in this trial (Aloia et al 2005). While mean serum 25-OHD levels significantly increased from 19.3 to $34.8 \mathrm{ng} / \mathrm{mL}(\mathrm{p}<0.001)$ in the vitamin D group, $40 \%$ of the women had $25-\mathrm{OHD}$ serum concentrations $<32 \mathrm{ng} / \mathrm{mL}$. Based on the results of this study, it may not be appropriate to extrapolate data on the dosing of vitamin D from studies of mostly white subjects to other racial and ethnic groups.

Not all vitamin D studies have demonstrated a beneficial effect on fractures and falls (Grant et al 2005; Porthouse et al 2005; Jackson et al 2006; Law et al 2006; Lyons et al 2007). The Women's Health Initiative Trial (WHI) did not show a reduction in fracture with calcium and vitamin D supplementation. However, subjects were randomized to receive 400 units/day cholecalciferol; a dose that did not demonstrate fracture risk reduction in the meta-analysis (Jackson et al 2006). In addition, adherence to therapy was poor with only $59 \%$ of subjects taking $80 \%$ or more of the assigned therapy at the end of the trial. When the results were analyzed excluding participants 6 months after nonadherence was detected, a statistically significant $29 \%$ relative reduction in hip fractures was demonstrated. The Record Trial evaluated 800 units/day oral cholecalciferol, $1000 \mathrm{mg}$ /day oral calcium, and the combination for secondary prevention of low-trauma fractures in elderly subjects (Grant et al 2005). There was no significant difference in the incidence of new, low-trauma fractures or falls between any of the groups. Adherence in this trial was also poor with only $54.5 \%$ of subjects still taking the therapy at 24 months. Vitamin D levels were obtained in 
only 60 subjects so the vitamin D status of the entire study population is unknown. In an open randomized controlled trial, elderly women with one or more risk factors for hip fracture received either 800 units/day oral cholecalciferol, $1000 \mathrm{mg} /$ day oral calcium, and educational information on calcium intake and fall prevention or just educational information (Porthouse et al 2005). Adherence rates in this study were also low (63\% at 12 months); however, when they analyzed the data only using women taking medication, there still was no reduction in fractures. Similar to the previous study, no vitamin D levels were obtained so the vitamin D status of the study population was unknown. In the WHI study, the dose was probably too low to affect fracture risk. In the other two studies that used 800 units per day; low adherence rates could have contributed to the negative findings. In addition, without data regarding the vitamin D status of the populations at baseline and after therapy, it is difficult to interpret the results of these studies.

There is no consensus on the most appropriate vitamin D supplementation regimen to maintain vitamin D sufficiency. The Institute of Medicine (IOM) currently recommends 400 units/day vitamin D for adults 50-70 years of age and 600 units/day for people over the age of 70 years (Melton et al 1997). The National Osteoporosis Foundation Guidelines recommend intakes of 800-1000 units/day for all persons 50 years of age and older (National Osteoporosis Foundation 2007). Several experts believe up to 1200 units/day vitamin D3 is needed to maintain 25-OHD levels at $>75-100 \mathrm{nmol} / \mathrm{L}(30-40 \mathrm{ng} / \mathrm{ml}$ ) (Holick 2003; Heaney 2004; Dawson-Hughes et al 2005; Grant and Holick 2005; Hanley and Davison 2005; Bischoff-Ferrari et al 2006). However, in the previously mentioned study of African American women, only $60 \%$ had sufficient $25-\mathrm{OHD}$ concentrations after supplementation at a dose of 2000 units/day for a year (Aloia et al 2005). Based on the meta-analysis, the minimum effective dose for preventing fractures appears to be 700-800 units/day (Bischoff-Ferrari et al 2005). Vitamin $\mathrm{D}$ has a wide margin of safety with hypercalcemia rarely occurring even at relatively high doses (Vieth 1999; Grant and Holick 2005). The IOM states the safe upper limit for vitamin D as 2000 units/day (Standing Committee on the Scientific Evaluation of Dietary Reference Intakes FaNB, Institute of Medicine 1997). In one study, doses as high as 4000 units/day were administered for up to 6 months without adverse consequence (Vieth et al 2001). It is evident that a reevaluation of the current vitamin D recommendations is needed. A National Institute of Health conference recently evaluated the efficacy and safety of vitamin $\mathrm{D}$ across all ages.
A detailed report is awaiting publication and it is anticipated that the recommended upper tolerable limit and daily allowance for vitamin $\mathrm{D}$ will be increased.

Very few foods are naturally high in or fortified with vitamin D. Therefore, to reach recommenced intakes, supplementation will be needed. Nonprescription vitamin D can be found in combination with calcium, as an individual supplement, or within the typical multivitamin. It is best to choose a product that has cholecalciferol, as ergocalciferol is considered to be less potent at increasing 25-OHD levels (Trang et al 1998). The average incremental increase in serum $25-\mathrm{OHD}$ has been estimated at $1.2 \mathrm{nmol} / \mathrm{L}(0.48 \mathrm{ng} / \mathrm{mL})$ for every 40 units of cholecalciferol given compared with only $3 \mathrm{nmol} / \mathrm{L}(0.12 \mathrm{ng} / \mathrm{mL}$ ) for ergocalciferol (Dawson-Hughes et al 2005). In addition, all the trials that demonstrated antifracture efficacy or reduction in falls have used cholecalciferol. It is unknown if supplementation with ergocalciferol would have the same benefits. High dose vitamin D is currently only available in the United States as ergocalciferol and requires a prescription.

Based on safety and efficacy data, it seems reasonable to recommend at least 800-1000 units cholecalciferol per day in all adults (Table 4). Higher doses may be needed in certain populations including ethnic and racial groups with darker skin pigmentation. If compliance is an issue, ergocalciferol 50,000 units orally once a month with periodic $25-\mathrm{OHD}$ monitoring has been used clinically for the long-term prevention of vitamin D deficiency (Holick 2007; Saab et al 2007). Another option would be oral cholecalciferol (ergocalciferol in the US) 100,000 units every 4 months, which was shown to reduce vertebral and nonvertebral fractures without adverse effects in a study of community-dwelling men and women aged 65 years and over (Trivedi et al 2003). Patients that are vitamin D deficient will require much higher doses of vitamin $\mathrm{D}$ to rapidly replete their stores into the sufficient range (Mastaglia et al 2006). Studies are lacking that evaluate treatment for vitamin D deficiency. Various regimens tend to be used clinically. Prescription oral ergocalciferol 50,000 units once weekly for 8 weeks or until levels are sufficient followed by a maintenance

Table 4 Suggested regimens for vitamin $D$ supplementation in adults $\geq 50$ years of age (Malabanan et al 1998; National Osteoporosis Foundation 2007)

\begin{tabular}{ll}
\hline Category & 25-hydroxyvitamin D \\
Deficient & 50,000 units oral ergocalciferol once weekly \\
& for 8 weeks or until sufficient level obtained \\
Insufficient & $800-1000$ units oral cholecalciferol daily \\
Sufficient & $800-1000$ units oral cholecalciferol daily \\
\hline
\end{tabular}


dose of 800-1000 units/day is a regimen that is frequently used in the United States (Malabanan et al 1998).

\section{Management of this patient}

It was appropriate to obtain a 25-OHD measurement in this patient due to the fact that she has a bone density test indicating osteoporosis, is African American and elderly. Based on her $25-\mathrm{OHD}$ concentration of $23 \mathrm{nmol} / \mathrm{L}$ ( $9 \mathrm{ng} / \mathrm{mL})$, she has vitamin D deficiency and is at risk for osteomalacia. Possible causes for vitamin D deficiency should be investigated (for example: medications known to interfere with vitamin D metabolism, symptoms consistent with Celiac Sprue, or other malabsorptive disease). Dietary and supplemental vitamin D consumption should be quantified. Since this patient is African American, her dark pigmented skin could contribute to her vitamin D deficiency, which means that her vitamin D requirements might be higher. This patient should initially receive treatment doses of vitamin $\mathrm{D}$ to replete her body stores. Prescription oral ergocalciferol 50,000 units once weekly for at least 8 weeks is typically used. A 25-OHD measurement should be repeated and if it is greater than or equal to $75 \mathrm{nmol} / \mathrm{L}$ ( $30 \mathrm{ng} / \mathrm{mL}$ ), the patient can be switched to maintenance therapy with at least 1000 units/day of oral cholecalciferol.

\section{Clinical challenge \#3: Treatment failure \\ Clinical scenario}

A 78-year-old Hispanic woman has been receiving alendronate $70 \mathrm{mg}$ orally once weekly for 2 years for the treatment of osteoporosis. The patient states that she is tolerating the therapy without difficulty and has been compliant with the regimen as prescribed. She has not suffered a fracture and there is also no change in measured height or curvature of spine. A repeat central DXA test was performed and the results are as follows.

\section{Baseline BMD}

- L1-L4 $0.983 \mathrm{~g} / \mathrm{cm}^{2}$, T-score -2.88

- Left Total Hip $0.779 \mathrm{~g} / \mathrm{cm}^{2}$, T-score -2.63

\section{Repeat BMD 2 years later}

- L1-L4 $0.942 \mathrm{~g} / \mathrm{cm}^{2}$, T-score -3.01: a 4.2\% decrease compared to the prior test

- Left Total Hip $0.760 \mathrm{~g} / \mathrm{cm}^{2}$, T-score -2.70: a $2.5 \%$ decrease compared to the prior test

Least significant change for this DXA machine

- Lumbar spine $(\mathrm{L} 1-\mathrm{L} 4)=4.0 \%$, Total hip $=3.4 \%$
The first issue is to define failure to respond to therapy. While this may at first seem relatively straightforward, it clearly is not. Any of 3 parameters can be used in making this determination: continuing loss of bone mass on therapy, failure of therapy to suppress biomarkers of bone turnover, or the occurrence of additional fractures on therapy. While all may provide important information, one must be aware of the pitfalls of using these criteria.

Serial BMD testing using central DXA is the standard of care for monitoring the response to therapy. In order to appropriately interpret the BMD results, the least significant change (LSC) value for the DXA machine used must be known (Miller et al 1999b; Cummings et al 2000; Bonnick et al 2001). The LSC is the smallest change that is considered to be a real change on a specific DXA machine. This value is calculated by multiplying the precision error of the machine by 2.77 . The LSC must be calculated on site for each individual machine on a regular basis (ideally weekly or monthly) and can be found on the DXA report. The LSC should be calculated for the absolute BMD change in $\mathrm{g} / \mathrm{cm}^{2}$ and not for the T-score or Z-score. Once the LSC for a particular DXA machine is known, serial measurements that are done on the same machine can then be interpreted properly. Serial BMD changes that meet or exceed the LSC are considered significant changes (gains or losses), whereas BMD changes that are less than the LSC or that come from entirely different DXA machines cannot be interpreted as true BMD changes. In clinical trials, subjects whose BMD increased were shown to have the greatest reductions in fracture risk. However, subjects whose BMD remained stable or decreased less than $4 \%$ were also shown to have significant reduction in fracture risk and it was only those, whose BMD decreased significantly, that had an unchanged fracture risk (Chapurlat et al 2005). Therefore, when serial BMD measurements are monitored, failure to respond to therapy is identified only when BMD, measured on the same DXA machine, decreases more than the known LSC for that specific machine.

Biomarkers of bone turnover can also be used to assess responses to therapy (Rosen et al 1997; Greenspan et al 1998; Miller et al 1999a). The most common biomarkers measured are urine n-telopeptides (NTX), urine or serum c-telopeptides (CTX), urine pyridinoline crosslinks, serum bone specific alkaline phosphatase (BSAP), and serum n-terminal propeptide of procollagen type 1 (P1NP). When using anti-resorptive therapy, one would expect suppression of biomarkers by $30 \%$ if pre-therapy values are available for comparison or to the lower end of the normal range when pre-therapy values are absent. A 30\% suppression of NTX 
after initiation of anti-resorptive therapy has been shown to be associated with a significant increase in both spine and hip BMD (Greenspan et al 1998). However, care must be taken in interpreting biomarkers because of the very significant diurnal variations and day-to-day variations that may, in many cases, exceed the changes resulting from therapy. Because of the significant variability inherent in their measurements, it is best to collect specimens at the same time of day (second morning voided urine, fasting morning blood) on each occasion. Variation can also be reduced by averaging the result of two measurements or by pooling two samples on consecutive days. Because of this significant variability, the exact role of biomarker assessment in monitoring therapy responses remains controversial.

Since low trauma fractures are the endpoint of interest in osteoporosis, it would seem that fractures occurring on therapy would be a sure indication of a therapeutic failure. The major published clinical trials have demonstrated vertebral and hip fracture reductions of $30 \%$ to $70 \%$ in patients on active osteoporosis therapy. (Black et al 1996; Ettinger et al 1999; Harris et al 1999; Chesnut et al 2000; McClung et al 2001; Neer et al 2001; Rossouw et al 2002; Meunier et al 2004; Black et al 2007). However, while the fracture risk was reduced by therapy, it was not entirely eliminated. Fractures continued to occur in both the treatment and the placebo groups, albeit at a lower rate in the treatment groups. Patients who are placed on osteoporosis therapy are those who are identified as being at high levels of risk. Risk reduction by improvements in BMD, bone remodeling, and bone quality is an achievable goal, whereas fracture elimination in a very high-risk population currently is not a realistic goal. Nonetheless, since low trauma fractures are generally a symptomatic endpoint, we often consider employing alternative or additional treatments when fractures continue to occur.

Once a failure to respond to therapy has been identified, the next step is to determine the cause of the inadequate response (Harper and Weber 1998; Tannenbaum et al 2002; Lewiecki 2003). Extensive clinical experience and limited published data suggest that the most common causes of failure to respond to osteoporosis therapy are those listed in Table 5. Poor adherence, defined here as not taking the medication regularly or not at all, is probably the most common cause overall. It has been well demonstrated that less than $50 \%$ of patients with osteoporosis remain on anti-resorptive therapy $1-1.5$ years after therapy is initiated (Lo et al 2006; van den Boogaard et al 2006). It is not entirely clear from such studies how many patients discontinued medication due
Table 5 Causes of failure to respond to osteoporosis therapy

Compliance issues: Not taking medication or not taking medication correctly Calcium nutritional deficiency: Inadequate calcium intake or absorption Vitamin D nutritional deficiency: Inadequate vitamin D intake or absorption Co-morbid conditions: Secondary bone loss

Medications: Secondary bone loss

Lack of efficacy of existing therapy

to side effects, but since serious side effects are relatively uncommon, it is likely that many patients simply stop their medications after brief periods of use. Deficient calcium and/or vitamin D intake or absorption is another cause that is significantly more widespread than is commonly appreciated (Holick et al 2005; Holick 2006). Inadequate circulating and interstitial calcium levels prevent adequate bone mineralization and limit or prevent the beneficial response to bone active agents. Co-morbid conditions that cause secondary bone loss and certain medications, some of which are summarized in Table 6, can also sabotage the response to otherwise effective bone therapy. It is only when all of the above have been carefully excluded that one can conclude that a therapy is simply not efficacious in a specific patient.

The evaluation of patients suspected to be failing to respond to therapy should begin with a complete history, with an emphasis on determining medication adherence and assessing intake and absorption of calcium and vitamin D. A thorough physical examination should also be performed. If compliance remains an unresolved issue, pharmacy records

Table 6 Selected secondary causes for osteoporosis (National Osteoporosis Foundation 2003; Painter et al 2006)

\begin{tabular}{|c|c|}
\hline Disease states & Drugs \\
\hline $1^{\circ}$ or $2^{\circ}$ ovarian failure & Systemic glucocorticoids \\
\hline Primary hyperparathyroidism & Excessive doses of levothyroxine \\
\hline Thyrotoxicosis & Most anticonvulsants \\
\hline Cushing's syndrome & $\begin{array}{l}\text { Depot medroxyprogesterone } \\
\text { acetate (DMPA) }\end{array}$ \\
\hline $\begin{array}{l}\text { Chronic liver disease- } \\
\text { (eg, Primary biliary cirrhosis) }\end{array}$ & $\begin{array}{l}\text { Cytotoxic chemotherapy } \\
\text { Gonadotropin-releasing hormone } \\
(\mathrm{GnRH}) \text { agonists such as leuprolide }\end{array}$ \\
\hline Celiac disease & Aromatase Inhibitors \\
\hline \multicolumn{2}{|l|}{ Inflammatory bowel disease } \\
\hline \multicolumn{2}{|l|}{ Other malabsorptive states } \\
\hline \multicolumn{2}{|l|}{ Growth hormone deficiency } \\
\hline \multicolumn{2}{|l|}{ Rheumatoid arthritis } \\
\hline \multicolumn{2}{|l|}{ Anorexia nervosa } \\
\hline \multicolumn{2}{|l|}{ Organ transplant } \\
\hline \multicolumn{2}{|l|}{ Chronic kidney disease } \\
\hline \multicolumn{2}{|l|}{ Malignancies } \\
\hline \multicolumn{2}{|l|}{ Hyperprolactinemia } \\
\hline \multicolumn{2}{|l|}{ Multiple myeloma } \\
\hline Chronic obstructive pulmonar & \\
\hline
\end{tabular}


may be requested or pill counts performed; testing for urine NTX may also be informative in this situation, since low to mid-normal values suggest that the patient is taking the medication, at least intermittently, whereas an elevated value adds evidence supporting noncompliance. In the patient who appears to be compliant, to be consuming adequate amounts of calcium and vitamin $\mathrm{D}$ and not to have obvious malabsorption, several key laboratory tests are recommended (Table 7). As discussed elsewhere in this manuscript, measurement of serum 25-OHD concentrations allows one to identify either vitamin D deficiency or vitamin D insufficiency. An elevated or high normal serum PTH value associated with hypercalcemia indicates the presence of primary hyperparathyroidism. An elevated or high normal serum PTH value in association with a mid-normal or lower serum calcium level or low urinary calcium excretion, suggests secondary hyperparathyroidism due to vitamin D deficiency, calcium deficiency, or chronic kidney failure. Measurement of tissue transglutaminase antibodies (for Celiac disease) should follow in any patient with low vitamin D levels, low urinary calcium excretion or secondary hyperparathyroidism not associated with chronic kidney failure. Depending upon the results, small bowel biopsies or radiographic studies for seronegative Celiac disease and other intestinal disorders should also be considered.

Bone biopsy and bone marrow biopsy seldom yield a diagnosis that is not already apparent after the above tests are completed. However, rare disorders such as systemic mastocytosis, may only be discovered by histological examination of the bone marrow. This procedure may therefore be indicated when the etiology of the bone disorder has otherwise remained elusive.

Management of the patient who is not responding to osteoporosis therapy may be relatively straightforward, depending on the underlying cause identified. The noncompliant patient should be educated and encouraged to take the medication as directed. Repeat BMD testing in follow-up has been shown to improve adherence among patients on these chronic medications, possibly because of the positive feedback that assures them that they are receiving benefit from being on the

Table 7 Suggested testing for the patient who is failing to respond to osteoporosis therapy

Serum testing
- $\quad$ Calcium, phosphorus, alkaline phosphatase, creatinine, CBC, ESR
- $\quad 25-\mathrm{OH} \mathrm{D,} \mathrm{PTH,TSH,} \mathrm{SPEP,} \mathrm{testosterone} \mathrm{(men)}$
Urine testing
- Calcium, N-telopeptides or other biomarkers

Abbreviations: $\mathrm{CBC}$, complete blood count; ESR, erythrocyte sedimentation rate 25-OH D, 25-hydroxyvitamin D; PTH, parathyroid hormone; TSH, thyroid-stimulating hormone; SPEP, serum protein electrophoresis. medication (Lo et al 2006). Patients with deficient calcium or vitamin $\mathrm{D}$ nutrition should be encouraged to consume adequate amounts of calcium (1000-1200 mg/day) and cholecalciferol (800-1000 units/day). If the 25-OHD level is below $10 \mathrm{ng} / \mathrm{mL}$, it is beneficial to restore the depleted vitamin $\mathrm{D}$ reserves to sufficient levels by administering a high-dose vitamin $\mathrm{D}$ regimen with repeated measurement of the 25-OHD after approximately 8 weeks of therapy.

When a nonresponding patient is determined to have good adherence, adequate calcium and vitamin D nutrition, and absence of co-morbid conditions that can cause bone loss, it may be reasonably concluded that the existing therapy in that patient is not efficacious. In these circumstances, a change or augmentation of therapy should be considered. It is an important fact that there are currently no published studies that have examined the efficacy of switching from one approved osteoporosis medication to another in a patient who appears to be failing to respond to the initial treatment. We therefore have no data that changing medications will be beneficial in these circumstances. However, it may be reasonable at this juncture to consider changing to a stronger medication or to a medication that has a different route of administration. Augmentation of therapy, by adding additional agents to existing therapy has engendered more interest in the research realm, but currently published data are inconclusive about the benefit of this maneuver. Combining two anti-resorptive agents together, such as a bisphosphonate plus estrogen, raloxifene or calcitonin, results in slightly but statistically significantly greater BMD increases than does one anti-resorptive agent alone (Lindsay et al 1999). However, there have been no published studies demonstrating that combinations of two anti-resorptive agents reduce the occurrence of low trauma fractures more than or even as well as anti-resorptive agent monotherapy. Combining an anti-resorptive agent with an anabolic agent has even greater theoretical appeal. However, two major studies utilizing the combination of alendronate and parathyroid hormone reported BMD gains that were generally similar to those seen with alendronate monotherapy and less than the BMD gains seen with parathyroid hormone monotherapy (Black et al 2003; Finkelstein et al 2003). Furthermore, no studies have adequately evaluated fracture reduction with combined anti-resorptive/anabolic agent regimens. Using anti-resorptive agents and anabolic agents sequentially, rather than concurrently, appears to have more promise, but remains under investigation (Black et al 2005)

Despite the absence of evidence that switching or adding agents provides any clear benefit in the patient who is not 
Table 8 Suggested therapy changes when initial osteoporosis medication is not efficacious

\begin{tabular}{ll}
\hline Current agent & New agent \\
\hline Raloxifene & Oral or IV bisphosphonate, strontium, teriparatide \\
Estrogens & Oral or IV bisphosphonate, strontium, teriparatide \\
Calcitonin & Oral or IV bisphosphonate, strontium, teriparatide \\
Oral bisphosphonate & IV bisphosphonate, teriparatide, strontium \\
IV bisphosphonate & Teriparatide, strontium \\
Teriparatide & Oral or IV bisphosphonate, strontium \\
\hline
\end{tabular}

responding to initial therapy, most practitioners would find it unacceptable to do nothing when a patient is experiencing progressive bone loss or additional fractures. Based on clinical experience and the sparse data available in the literature, our suggestions for altering therapy in these circumstances are shown in Table 8. Patients who are failing to respond to raloxifene, estrogen, strontium or calcitonin should, in most cases, be switched to oral bisphosphonate therapy. Those who have had previous gastrointestinal side effects with oral bisphosphonates can be changed to an IV bisphosphonate. IV bisphosphonates are also reasonable if one has any reason to believe that oral bisphosphonates are not being adequately absorbed into the circulation (eg, persistent elevation of urine n-telopeptides in a patient with good adherence on an oral bisphosphonate). In addition to being a good choice for primary therapy, teriparatide is also a good option for patients who have not responded to or who have not tolerated anti-resorptive therapy. Those who fail to respond to primary therapy with teriparatide should be changed to an oral or IV bisphosphonate.

\section{Management of this patient}

This patient had a clinically significant reduction of BMD at the lumbar spine, exceeding the LSC, and to a T-score of $<-3.0$, while compliant on therapy with an FDA-approved oral bisphosphonate. If not already done, this patient should be evaluated for possible secondary causes of bone loss. There are no published data that switching from an oral to an intravenous bisphosphonate is beneficial in compliant patients that are tolerating oral therapy. If no correctable cause for this patient's nonresponse to therapy can be identified, the next step in this patient would be to consider discontinuing alendronate therapy and initiating a 2-year course of teriparatide.

\section{Conclusion}

Significant advances have been made in the evaluation and treatment of osteoporosis; however many clinical scenarios exist where consensus recommendations are lacking or controversy exists regarding appropriate management.
This review summarizes three such clinical challenges and provides the primary care provider with practical information to help them make rational choices when presented with similar patient scenarios in clinical practice.

\section{References}

Aloia JF, Talwar SA, Pollack S, et al. 2005. A randomized controlled trial of vitamin D3 supplementation in African American women. Arch Intern Med, 165:1618-23.

Barrett-Connor E, Mosca L, Collins P, et al. 2006. Effects of raloxifene on cardiovascular events and breast cancer in postmenopausal women. N Engl J Med, 355:125-37.

Binkley N, Krueger D, Cowgill CS, et al. 2004. Assay variation confounds the diagnosis of hypovitaminosis D: a call for standardization. J Clin Endocrinol Metab, 89:3152-7.

Bischoff-Ferrari HA, Dawson-Hughes B, Willett WC, et al. 2004. Effect of vitamin D on falls: a meta-analysis. JAMA, 291:1999-2006.

Bischoff-Ferrari HA, Giovannucci E, Willett WC, et al. 2006. Estimation of optimal serum concentrations of 25-hydroxyvitamin D for multiple health outcomes. Am J Clin Nutr, 84:18-28.

Bischoff-Ferrari HA, Willett WC, Wong JB, et al. 2005. Fracture prevention with vitamin D supplementation: a meta-analysis of randomized controlled trials. JAMA, 293:2257-64.

Bischoff HA, Stahelin HB, Dick W, et al. 2003. Effects of vitamin D and calcium supplementation on falls: a randomized controlled trial. J Bone Miner Res, 18:343-51.

Black DM, Bilezikian JP, Ensrud KE, et al. 2005. One year of alendronate after one year of parathyroid hormone (1-84) for osteoporosis. $N \mathrm{Engl}$ J Med, 353:555-65.

Black DM, Cummings SR, Karpf DB, et al. 1996. Randomised trial of effect of alendronate on risk of fracture in women with existing vertebral fractures. Fracture Intervention Trial Research Group [comment]. Lancet, 348:1535-41.

Black DM, Delmas PD, Eastell R, et al. 2007. Once-yearly zoledronic acid for treatment of postmenopausal osteoporosis. $N$ Engl $\mathrm{J} \mathrm{Med,}$ 356:1809-22.

Black DM, Greenspan SL, Ensrud KE, et al. 2003. The effects of parathyroid hormone and alendronate alone or in combination in postmenopausal osteoporosis. N Engl J Med, 349:1207-15.

Black DM, Schwartz AV, Ensrud KE, et al. 2006. Effects of continuing or stopping alendronate after 5 years of treatment: the Fracture Intervention Trial Long-term Extension (FLEX): a randomized trial. JAMA, 296:2927-38.

Bonnick SL, Johnston CC, Jr., Kleerekoper M, et al. 2001. Importance of precision in bone density measurements. J Clin Densitom, 4:105-10.

Bouxsein ML 2005. Determinants of skeletal fragility. Best Pract Res Clin Rheumatol, 19:897-911.

Broe KE, Chen TC, Weinberg J, et al. 2007. A higher dose of vitamin D reduces the risk of falls in nursing home residents: a randomized, multiple-dose study. J Am Geriatr Soc, 55:234-9.

Chapurlat RD, Palermo L, Ramsay P, et al. 2005. Risk of fracture among women who lose bone density during treatment with alendronate. The Fracture Intervention Trial. Osteoporos Int, 16:842-8.

Chapuy MC, Arlot ME, Delmas PD, et al. 1994. Effect of calcium and cholecalciferol treatment for three years on hip fractures in elderly women. BMJ, 308:1081-2.

Chapuy MC, Arlot ME, DuboeufF, et al. 1992. Vitamin D3 and calcium to prevent hip fractures in the elderly women. $N$ Engl J Med, 327:1637-42.

Chapuy MC, Pamphile R, Paris E, et al. 2002. Combined calcium and vitamin D3 supplementation in elderly women: confirmation of reversal of secondary hyperparathyroidism and hip fracture risk: the Decalyos II study. Osteoporos Int, 13:257-64.

Chapuy MC, Preziosi P, Maamer M, et al. 1997. Prevalence of vitamin $\mathrm{D}$ insufficiency in an adult normal population. Osteoporos Int, 7:439-43. 
Chesnut CH, 3rd, Silverman S, Andriano K, et al. 2000. A randomized trial of nasal spray salmon calcitonin in postmenopausal women with established osteoporosis: the prevent recurrence of osteoporotic fractures study. PROOF Study Group [comment]. Am J Med, 109:267-76.

Chesnut IC, Skag A, Christiansen C, et al. 2004. Effects of oral ibandronate administered daily or intermittently on fracture risk in postmenopausal osteoporosis. J Bone Miner Res, 19:1241-9.

Cummings SR, Palermo L, Browner W, et al. 2000. Monitoring osteoporosis therapy with bone densitometry: misleading changes and regression to the mean. Fracture Intervention Trial Research Group. JAMA, 283:1318-21.

Dawson-Hughes B, Harris SS, Krall EA, et al. 1997. Effect of calcium and vitamin D supplementation on bone density in men and women 65 years of age or older. $N$ Engl J Med, 337:670-6.

Dawson-Hughes B, Heaney RP, Holick MF, et al. 2005. Estimates of optimal vitamin D status. Osteoporos Int, 16:713-16.

Delmas PD, Adami S, Strugala C, et al. 2006. Intravenous ibandronate injections in postmenopausal women with osteoporosis: one-year results from the dosing intravenous administration study. Arthritis Rheum, 54:1838-46.

Dhesi JK, Bearne LM, Moniz C, et al. 2002. Neuromuscular and psychomotor function in elderly subjects who fall and the relationship with vitamin D status. J Bone Miner Res, 17:891-7.

Dhesi JK, Jackson SH, Bearne LM, et al. 2004. Vitamin D supplementation improves neuromuscular function in older people who fall. Age Ageing, 33:589-95.

Ettinger B, Black DM, Mitlak BH, et al. 1999. Reduction of vertebral fracture risk in postmenopausal women with osteoporosis treated with raloxifene: results from a 3-year randomized clinical trial. Multiple Outcomes of Raloxifene Evaluation (MORE) Investigators. JAMA, 282:637-45.

Felsenberg D, Boonen S. 2005. The bone quality framework: determinants of bone strength and their interrelationships, and implications for osteoporosis management. Clin Ther, 27:1-11.

Finkelstein JS, Hayes A, Hunzelman JL, et al. 2003. The effects of parathyroid hormone, alendronate, or both in men with osteoporosis. $N$ Engl $J$ Med, 349:1216-26.

Flicker L, MacInnis RJ, Stein MS, et al. 2005. Should older people in residential care receive vitamin $D$ to prevent falls? Results of a randomized trial. J Am Geriatr Soc, 53:1881-8.

Glendenning P, Fraser WD. 2005. 25-OH-vitamin D assays. J Clin Endocrinol Metab, 90:3129.

Grant AM, Avenell A, Campbell MK, et al. 2005. Oral vitamin D3 and calcium for secondary prevention of low-trauma fractures in elderly people (Randomised Evaluation of Calcium Or vitamin D, RECORD) a randomised placebo-controlled trial. Lancet, 365:1621-8.

Grant WB, Holick MF. 2005. Benefits and requirements of vitamin D for optimal health: a review. Alt Med Rev, 10:94-111.

Greenspan SL, Parker RA, Ferguson L, et al. 1998. Early changes in biochemical markers of bone turnover predict the long-term response to alendronate therapy in representative elderly women: a randomized clinical trial. J Bone Miner Res, 13:1431-8.

Greenspan SL, Resnick NM, Parker RA. 2005. Vitamin D supplementation in older women. J Gerontol A Biol Sci Med Sci, 60:754-9.

Hanley DA, Davison KS. 2005. Vitamin D insufficiency in North America. $J$ Nutr, 135:332-7.

Harper KD, Weber TJ. 1998. Secondary osteoporosis. Diagnostic considerations. Endocrinol Metab Clin North Am, 27:325-48.

Harris SS, Soteriades E, Coolidge JA, et al. 2000. Vitamin D insufficiency and hyperparathyroidism in a low income, multiracial, elderly population. J Clin Endocrinol Metab, 85:4125-30.

Harris ST, Watts NB, Genant HK, et al. 1999. Effects of risedronate treatment on vertebral and nonvertebral fractures in women with postmenopausal osteoporosis: a randomized controlled trial. Vertebral Efficacy With Risedronate Therapy (VERT) Study Group. JAMA, 282:1344-52.

Heaney RP. 2004. Functional indices of vitamin D status and ramifications of vitamin D deficiency. Am J Clin Nutr, 80:1706S-9S.
Heaney RP, Dowell MS, Hale CA, et al. 2003. Calcium absorption varies within the reference range for serum 25 -hydroxyvitamin D. J Am Coll Nutr, 22:142-6.

Holick MF. 2003. Vitamin D deficiency: what a pain it is. Mayo Clin Proc, 78:1457-9.

Holick MF. 2005. 25-OH-vitamin D assays. J Clin Endocrinol Metab, 90:3128-9.

Holick MF. 2006. High prevalence of vitamin D inadequacy and implications for health. Mayo Clin Proc, 81:353-73.

Holick MF. 2007. Vitamin D deficiency. N Engl J Med, 357:266-81.

Holick MF, Siris ES, Binkley N, et al. 2005. Prevalence of Vitamin D inadequacy among postmenopausal North American women receiving osteoporosis therapy. J Clin Endocrinol Metab, 90:3215-24.

Hosking D, Chilvers CE, Christiansen C, et al. 1998. Prevention of bone loss with alendronate in postmenopausal women under 60 years of age. Early Postmenopausal Intervention Cohort Study Group. $N$ Engl J Med, 338:485-92.

Jackson RD, LaCroix AZ, Gass M, et al. 2006. Calcium plus vitamin D supplementation and the risk of fractures. $N$ Engl $J$ Med, 354:669-83.

Kanis JA. 2002. Diagnosis of osteoporosis and assessment of fracture risk. Lancet, 359:1929-36.

Kanis JA, Black D, Cooper C, et al. 2002. A new approach to the development of assessment guidelines for osteoporosis. Osteoporos Int, 13:527-36.

Kanis JA, Borgstrom F, De Laet C, et al. 2005. Assessment of fracture risk. Osteoporos Int, 16:581-9.

Kanis JA, Gluer CC. 2000. An update on the diagnosis and assessment of osteoporosis with densitometry. Committee of Scientific Advisors, International Osteoporosis Foundation. Osteoporos Int, $11: 192-202$.

Kanis JA, Johnell O, Black DM, et al. 2003. Effect of raloxifene on the risk of new vertebral fracture in postmenopausal women with osteopenia or osteoporosis: a reanalysis of the Multiple Outcomes of Raloxifene Evaluation trial. Bone, 33: 293-300.

Kanis JA, Johnell O, Oden A, et al. 2001a. Ten year probabilities of osteoporotic fractures according to BMD and diagnostic thresholds. Osteoporos Int, 12:989-95.

Kanis JA, Oden A, Johnell O, et al. 2007. The use of clinical risk factors enhances the performance of BMD in the prediction of hip and osteoporotic fractures in men and women. Osteoporos Int, $18: 1033-46$

Kanis JA, Oden A, Johnell O, et al. 2001b. The burden of osteoporotic fractures: a method for setting intervention thresholds. Osteoporos Int, 12:417-27.

Lappe JM, Travers-Gustafson D, Davies KM, et al. 2007. Vitamin D and calcium supplementation reduces cancer risk: results of a randomized trial. Am J Clin Nutr, 85:1586-91.

Law M, Withers H, Morris J, et al. 2006. Vitamin D supplementation and the prevention of fractures and falls: results of a randomised trial in elderly people in residential accommodation. Age Ageing, 35:482-6.

LeBoff MS, Kohlmeier L, Hurwitz S, et al. 1999. Occult vitamin D deficiency in postmenopausal US women with acute hip fracture. JAMA, 281:1505-11.

Leventis P, Garrison L, Sibley M, et al. 2005. Underestimation of serum 25-hydroxyvitamin D by the Nichols Advantage Assay in patients receiving vitamin D replacement therapy. Clin Chem, 51:1072-4; author reply 1074 .

Levis S, Gomez A, Jimenez C, et al. 2005. Vitamin d deficiency and seasonal variation in an adult South Florida population. J Clin Endocrinol Metab, 90:1557-62.

Lewiecki EM. 2003. Nonresponders to osteoporosis therapy. J Clin Densitom, 6:307-14.

Lindsay R, Cosman F, Lobo RA, et al. 1999. Addition of alendronate to ongoing hormone replacement therapy in the treatment of osteoporosis: a randomized, controlled clinical trial. J Clin Endocrinol Metab, 84:3076-81. 
Lips P, Duong T, Oleksik A, et al. 2001. A global study of vitamin D status and parathyroid function in postmenopausal women with osteoporosis: baseline data from the multiple outcomes of raloxifene evaluation clinical trial. J Clin Endocrinol Metab, 86:1212-21.

Lips P, Graafmans WC, Ooms ME, et al. 1996. Vitamin D supplementation and fracture incidence in elderly persons. A randomized, placebocontrolled clinical trial. Ann Intern Med, 124:400-6.

Lo JC, Pressman AR, Omar MA, et al. 2006. Persistence with weekly alendronate therapy among postmenopausal women. Osteoporos Int, 17:922-8.

Lock CA, Lecouturier J, Mason JM, et al. 2006. Lifestyle interventions to prevent osteoporotic fractures: a systematic review. Osteoporos Int, 17:20-8.

Lyons RA, Johansen A, Brophy S, et al. 2007. Preventing fractures among older people living in institutional care: a pragmatic randomised double blind placebo controlled trial of vitamin D supplementation. Osteoporos Int, 18:811-18.

Malabanan A, Veronikis IE, Holick MF. 1998. Redefining vitamin D insufficiency. Lancet, 351:805-6.

Martins D, Wolf M, Pan D, et al. 2007. Prevalence of cardiovascular risk factors and the serum levels of 25-hydroxyvitamin D in the United States: data from the Third National Health and Nutrition Examination Survey. Arch Intern Med, 167:1159-65.

Mastaglia SR, Mautalen CA, Parisi MS, et al. 2006. Vitamin D2 dose required to rapidly increase $25 \mathrm{OHD}$ levels in osteoporotic women. Eur J Clin Nutr, 60:681-7.

McClung MR, Geusens P, Miller PD, et al. 2001. Effect of risedronate on the risk of hip fracture in elderly women. Hip Intervention Program Study Group. N Engl J Med, 344:333-40.

Melton LJ, 3rd, Lane AW, Cooper C, et al. 1993. Prevalence and incidence of vertebral deformities. Osteoporos Int, 3:113-19.

Melton LJ, 3rd, Thamer M, Ray NF, et al. 1997. Fractures attributable to osteoporosis: report from the National Osteoporosis Foundation. J Bone Miner Res, 12:16-23.

Meunier PJ, Roux C, Seeman E, et al. 2004. The effects of strontium ranelate on the risk of vertebral fracture in women with postmenopausal osteoporosis. $N$ Engl J Med, 350:459-68.

Meunier PJ, Slosman DO, Delmas PD, et al. 2002. Strontium ranelate: dose-dependent effects in established postmenopausal vertebral osteoporosis--a 2-year randomized placebo controlled trial. J Clin Endocrinol Metab, 87:2060-6.

Miller PD, Baran DT, Bilezikian JP, et al. 1999a. Practical clinical application of biochemical markers of bone turnover: Consensus of an expert panel. J Clin Densitom, 2:323-42.

Miller PD, Barlas S, Brenneman SK, et al. 2004. An approach to identifying osteopenic women at increased short-term risk of fracture. Arch Intern Med, 164:1113-20.

Miller PD, Siris ES, Barrett-Connor E, et al. 2002. Prediction of fracture risk in postmenopausal white women with peripheral bone densitometry: evidence from the National Osteoporosis Risk Assessment. $J$ Bone Miner Res, 17:2222-30.

Miller PD, Zapalowski C, Kulak CA, et al. 1999b. Bone densitometry: the best way to detect osteoporosis and to monitor therapy. J Clin Endocrinol Metab, 84:1867-71.

Mortensen L, Charles P, Bekker PJ, et al. 1998. Risedronate increases bone mass in an early postmenopausal population: two years of treatment plus one year of follow-up. J Clin Endocrinol, 83:396-402.

National Osteoporosis Foundation. 2003. Physician's guide to prevention and treatment of osteoporosis. National Osteoporosis Foundation, Washington, DC.

National Osteoporosis Foundation. 2007. Updated recommendations for calcium and vitamin D intake [online]. Accessed on 24 December, 2007. URL: http://www.nof.org/prevention/calcium_and_VitaminD. htm.

Neer RM, Arnaud CD, Zanchetta JR, et al. 2001. Effect of parathyroid hormone (1-34) on fractures and bone mineral density in postmenopausal women with osteoporosis. N Engl J Med, 344:1434-41.
Nesby-O’Dell S, Scanlon KS, Cogswell ME, et al. 2002. Hypovitaminosis $\mathrm{D}$ prevalence and determinants among African American and white women of reproductive age: third National Health and Nutrition Examination Survey, 1988-1994. Am J Clin Nutr, 76:187-92.

O'Donnell S, Cranney A, Wells GA, et al. 2006. Strontium ranelate for preventing and treating postmenopausal osteoporosis. Cochrane Database Syst Rev, 4:CD005326.

Painter SE, Kleerekoper M, Camacho PM. 2006. Secondary osteoporosis: a review of the recent evidence. Endocr Pract, 12:436-45.

Pasco JA, Henry MJ, Kotowicz MA, et al. 2004. Seasonal periodicity of serum vitamin D and parathyroid hormone, bone resorption, and fractures: the Geelong Osteoporosis Study. J Bone Miner Res, 19:752-8.

Pasco JA, Seeman E, Henry MJ, et al. 2006. The population burden of fractures originates in women with osteopenia, not osteoporosis. Osteoporos Int, 17:1404-9.

Pfeifer M, Begerow B, Minne HW. 2002. Vitamin D and muscle function. Osteoporos Int, 13:187-94.

Pfeifer M, Begerow B, Minne HW, et al. 2000. Effects of a short-term vitamin D and calcium supplementation on body sway and secondary hyperparathyroidism in elderly women. $J$ Bone Miner Res, 15:1113-18.

Porthouse J, Cockayne S, King C, et al. 2005. Randomised controlled trial of calcium and supplementation with cholecalciferol (vitamin D3) for prevention of fractures in primary care. $B M J, 330: 1003$.

Quandt SA, Thompson DE, Schneider DL, et al. 2005. Effect of alendronate on vertebral fracture risk in women with bone mineral density $\mathrm{T}$ scores of-1.6 to -2.5 at the femoral neck: the Fracture Intervention Trial. Mayo Clin Proc, 80:343-9.

Reginster JY. 2005. The high prevalence of inadequate serum vitamin D levels and implications for bone health. Curr Med Res Opin, 21:579-86.

Reginster JY, Deroisy R, Dougados M, et al. 2002. Prevention of early postmenopausal bone loss by strontium ranelate: the randomized, twoyear, double-masked, dose-ranging, placebo-controlled PREVOS trial. Osteoporos Int, 13:925-31.

Reginster JY, Seeman E, De Vernejoul MC, et al. 2005. Strontium ranelate reduces the risk of nonvertebral fractures in postmenopausal women with osteoporosis: Treatment of Peripheral Osteoporosis (TROPOS) study. J Clin Endocrinol Metab, 90:2816-22.

Rosen CJ, Chesnut CH, 3rd, Mallinak NJ. 1997. The predictive value of biochemical markers of bone turnover for bone mineral density in early postmenopausal women treated with hormone replacement or calcium supplementation. J Clin Endocrinol Metab, 82:1904-10.

Rossouw JE, Anderson GL, Prentice RL, et al. 2002. Risks and benefits of estrogen plus progestin in healthy postmenopausal women: principal results From the Women's Health Initiative randomized controlled trial. JAMA, 288:321-33.

Saab G, Young DO, Gincherman Y, et al. 2007. Prevalence of vitamin D deficiency and the safety and effectiveness of monthly ergocalciferol in hemodialysis patients. Nephron Clin Pract, 105:c132-8.

Sarkar S, Mitlak BH, Wong M, et al. 2002. Relationships between bone mineral density and incident vertebral fracture risk with raloxifene therapy. J Bone Miner Res, 17:1-10.

Schousboe JT, Ensrud KE, Nyman JA, et al. 2005a. Potential cost-effective use of spine radiographs to detect vertebral deformity and select osteopenic post-menopausal women for amino-bisphosphonate therapy. Osteoporos Int, 16:1883-93.

Schousboe JT, Nyman JA, Kane RL, et al. 2005b. Cost-effectiveness of alendronate therapy for osteopenic postmenopausal women. Ann Intern Med, 142:734-41.

Schuit SC, van der Klift M, Weel AE, et al. 2004. Fracture incidence and association with bone mineral density in elderly men and women: the Rotterdam Study. Bone, 34:195-202.

Siris ES, Chen YT, Abbott TA, et al. 2004. Bone mineral density thresholds for pharmacological intervention to prevent fractures. Arch Intern Med, 164:1108-12. 
Siris ES, Harris ST, Rosen CJ, et al. 2006. Adherence to bisphosphonate therapy and fracture rates in osteoporotic women: relationship to vertebral and nonvertebral fractures from 2 US claims databases. Mayo Clin Proc, 81:1013-22.

Siris ES, Miller PD, Barrett-Connor E, et al. 2001. Identification and fracture outcomes of undiagnosed low bone mineral density in postmenopausal women: results from the National Osteoporosis Risk Assessment. JAMA, 286:2815-22.

Small RE. 2005. Uses and limitations of bone mineral density measurements in the management of osteoporosis. Med Gen Med, 7:3.

Sornay-Rendu E, Munoz F, Garnero P, et al. 2005. Identification of osteopenic women at high risk of fracture: the OFELY study. $J$ Bone Miner Res, 20:1813-19.

Standing Committee on the Scientific Evaluation of Dietary Reference Intakes Food and Nutrition Board, Institute of Medicine. 1997. Dietary Reference Intakes for Calcium, Phosphorus, Magnesium, Vitamin D and Fluoride. Washington DC, The National Academies Press.

Stein MS, Wark JD, Scherer SC, et al. 1999. Falls relate to vitamin D and parathyroid hormone in an Australian nursing home and hostel. $J \mathrm{Am}$ Geriatr Soc, 47:1195-201.

Tannenbaum C, Clark J, Schwartzman K, et al. 2002. Yield of laboratory testing to identify secondary contributors to osteoporosis in otherwise healthy women. J Clin Endocrinol Metab, 87:4431-7.

The North American Menopause Society. 2006. Management of osteoporosis in postmenopausal women: 2006 position statement of The North American Menopause Society. Menopause, 13:340-67; quiz 368-9.

The North American Menopause Society. 2007. Estrogen and progestogen use in peri- and postmenopausal women: March 2007 position statement of The North American Menopause Society. Menopause, 14:168-82.

Thomas MK, Lloyd-Jones DM, Thadhani RI, et al. 1998. Hypovitaminosis $\mathrm{D}$ in medical inpatients. $N$ Engl J Med, 338:777-83.

Trang HM, Cole DE, Rubin LA, et al. 1998. Evidence that vitamin D3 increases serum 25-hydroxyvitamin D more efficiently than does vitamin D2. Am J Clin Nutr, 68:854-8.
Trivedi DP, Doll R, Khaw KT. 2003. Effect of four monthly oral vitamin D3 (cholecalciferol) supplementation on fractures and mortality in men and women living in the community: randomised double blind controlled trial. $B M J, 326: 469$.

US Department of Health and Human Services. 2004. Bone health and osteoporosis: a report of the Surgeon General Rockville, MD: U.S. Department of Health and Human Services, Office of the Surgeon General.

van den Boogaard CH, Breekveldt-Postma NS, Borggreve SE, et al. 2006. Persistent bisphosphonate use and the risk of osteoporotic fractures in clinical practice: a database analysis study. Curr Med Res Opin, 22:1757-64

van der Wielen RP, Lowik MR, van den Berg H, et al. 1995. Serum vitamin D concentrations among elderly people in Europe. Lancet, 346:207-10.

Vieth R. 1999. Vitamin D supplementation, 25-hydroxyvitamin D concentrations, and safety. Am J Clin Nutr, 69:842-56.

Vieth R. 2005. The role of vitamin D in the prevention of osteoporosis. Ann Med, 37:278-85.

Vieth R, Chan PC, MacFarlane GD. 2001. Efficacy and safety of vitamin D3 intake exceeding the lowest observed adverse effect level. Am J Clin Nutr, 73:288-94.

Vogel VG, Costantino JP, Wickerham DL, et al. 2006. Effects of tamoxifen vs raloxifene on the risk of developing invasive breast cancer and other disease outcomes: the NSABP Study of Tamoxifen and Raloxifene (STAR) P-2 trial. JAMA, 295:2727-41.

Wainwright SA, Marshall LM, Ensrud KE, et al. 2005. Hip fracture in women without osteoporosis. J Clin Endocrinol Metab, 90:2787-93.

Weycker D, Macarios D, Edelsberg J, et al. 2007. Compliance with osteoporosis drug therapy and risk of fracture. Osteoporos Int, 18:271-7.

Wooltorton E. 2006. Osteoporosis treatment: raloxifene (Evista) and stroke mortality. CMAJ, 175:147. 
